\title{
An empirical investigation on the effects of electronic banking on key customer relationship management
}

\author{
Kazem Chavoshi $^{\mathrm{a}}$, Ali Ramezanzadeh ${ }^{\mathrm{b}^{*}}$, Sohrab Ahmadvand ${ }^{\mathrm{c}}$, Kianoush Nazari Amaleh ${ }^{\mathrm{d}}$ and Behnam \\ Rezaei $^{\mathrm{e}}$
}

\begin{tabular}{l}
${ }^{a}$ Assistant Professor, Economic Sciences University, Tehran, Iran \\
${ }^{b}$ Master of Business Management, Department of Accounting \& Management, Allameh Tabataba'i University, Tehran, Iran \\
${ }^{c}$ Department of Business Management, Qom Branch, Islamic Azad University, Qom, Iran \\
${ }^{d}$ Department of Business Management, Science and Research Branch, Islamic Azad University, Tehran, Iran \\
${ }^{e}$ Master of Business Management, Department of Accounting \& Management, Allameh Tabataba'i University, Tehran, Iran \\
\hline C H R O N I C L E
\end{tabular}

Article history:

Received May 12, 2013

Received in revised format

12 September 2013

Accepted 7 October 2013

Available online

October 222013

Keywords:

ATM

CRM

Electronic banking (e-banking)

Internet banking

Mobile banking

Telephone banking

\section{A B S T R A C T}

In recent years, there has been good progress on information and communication technology influencing businesses with a new emerging concept called customer relationship management (CRM) and it has made significant changes in electronic banking. The primary objective of this paper is to survey electronic banking effects on key CRM components in one of Iranian banks in city of Tehran, Iran. The survey designs a questionnaire and distributes it among some experts in one of selected regions and the results are verified based on t-student and Freedman tests. Results show that all electronic banking services influence on CRM. In addition, that there are no significant differences among effects of electronic services on CRM but each CRM component has different effects on electronic services. In fact, according to freedman test, improving customer relationship process is the most important factor followed by providing appropriate service for each customer, providing appropriate service on appropriate time for each customer and providing appropriate service by appropriate channel for each customer.

\section{Introduction}

During the past few years, there have been tremendous changes on relationship between vendors and buyers. These days, the relationship between buyers and sellers mostly depends on countries' economic growth, immigrations from rural areas to cities and competition. In recent years, information technology (IT) has contributed to industry, significantly through providing customer relationship management (CRM) over many IT based infrastructures.

There is a simple idea that considers different customers who demand various goods and instead of mass marketing, each customer is marketed, individually. In this approach, the information for each 
customer including previous purchases, needs and demands are utilized for making an adaptable framework, which would increase customers' demand (Buttle, 2012; Kumar, 2010). IT-CRM as a customer-oriented strategy is increasingly used by different companies and banks and there are a lot of investments on this method (Kim et al., 2010). To implement customer-orientation, some important issues like accountability to customer demand i.e. service diversification and new initiative services have to be taken into account. Regarding electronic world concept in these days, banks must use electronic banking tools and patterns to be successful (Ayadi, 1996). In recent years, many banks have spent large amount of budgets to develop electronic banking services to increase competition. These services have developed for all the society and many Iranian banks such as Mellat Bank, Tejarat bank and Saderat bank try to encourage their customers to switch to newly introduced online banking. Therefore, many banks look for services used in all societies to increase their profitability and surviving remains as the main goal for a private bank. In addition, it must be mentioned that the main profitability of a bank comes from few number of customers. Banks must concentrate their budget on innovative services, which benefit customers and revise their previous services although all the society can benefit from these services. We must investigate to see if changes in the bank's structure is favorable to benefit customers and has its potential to absorb and maintain customers; on the other hand to see whether electronic banking services help us reach CRM goals or not. In this study we seek to measure electronic banking services effects on CRM and also to determine each component of electronic services.

\section{Materials and methods}

\subsection{Literature review}

CRM is a system, which assists organization in maintaining a long- term relationship with customer designed based on win-win strategy and is profitable and valuable for both sides. Every interact is an opportunity i.e. it is not only selling services but also organizations can obtain useful information from customers to improve organizational learning and hence finding new ideas and interests. CRM is a comprehensive business strategy, which integrates technology, processes and activities around customer by creating individual relationship, using accounts information (Devlin et al., 1997).

First strategy of marketing is to develop competitive advantage (Devlin et al., 1997). Conventional marketing strategies were based on 4P's to increase market share including Price, Product, promotion and Place. The primary objective of this kind of marketing is to increase seller and buyer's trade volume (Wyner, 1999) but CRM is a business strategy that is more beyond increasing trade volume (Urgu.com, 2002). In CRM for maintaining a long-term relationship with customers, various concepts like knowledge management, data mining and data pool are combined together (Salami, 2005). CRM is a strategy, which aims understanding, forecasting and managing current and potential customers. CRM is a technique, which enables organization investment towards managing customer behavior. This means aligning strategy with organizational culture and customer information and IT, which promotes a bilateral relationship between organization and customer (Salami, 2005). Scholars have defined various objectives for CRM. According to Barnett (2001), CRM is able to increase revenue, improving success, increasing profitability, increasing customer satisfaction, decreasing clerical, marketing and sales expenditures. Novel (2000) stated CRM as recognizing each customer value, recognizing relative importance of each need, determining whether these values are influencing positively organizational objectives, offering appropriate values as they wants, measuring results and returns. According to Swift (2001), CRM is improving relationship with real customer, offering appropriate products and services to customer, offering appropriate services by appropriate channels to customer, offering appropriate service in appropriate time. According to Kalakota and Robinson (1999), CRM is capable of increasing revenue, using relationship with customers, using integrated data for better services and introducing compatible methods (Buttle, 2012; Kumar, 2010). CRM is comprised from 3 components; customer, relationship and management (See Fig. 1). 


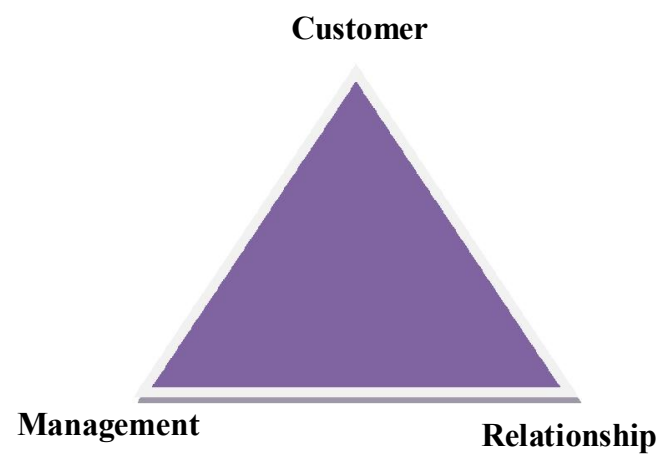

Fig. 1. CRM components

Customer is the only source of future growth, CRM can be assumed as a method of marketing by using customer information. The relationship between organization and customers consist of a bilateral and ongoing connection. The relationship can be long-term or short-term, continuous or discontinuous, repetitive or sudden. Even if customers have positive attitudes with organization and its products, it is important to treat them with respect in purchasing occasions. CRM is not an activity in marketing division and it is clearly a permanent organizational evolution in cultures. Customer information changes to organizational knowledge thus it enables acting in a way using market opportunities (urgu.com, 2002). CRM is importance in banking and most banks, collecting liquidity from customer's deposits, must place customer-orientation as primary element of its activity (Meyer $\&$ Schwager, 2007). Nowadays, regarding competitive environment and aggressive strategies, CRM plays essential role on customer retention (Salami, 2005). It is essential for banks to know customers well and to hold a strong and trusted relationship in financial services sector (Diacon et al., 1996). CRM cause commitment, loyalty and cooperation between organization and customers (Tyler et al., 1999). Studies show that banks with appropriate CRM can maintain big competitions in the market (Bennett et al. 2002). For instance, studies in US banking industry showed, banks that developed customer-orientation strategies have gained more profit (Diacon et al., 1996). CRM comprises six main stimuli including targeting, continuous contact with customer, forecasting effective customer for future, absorbing customer, using master or subsidiary sales techniques, creating loyalty with appropriate services and maintaining and reserving customers (Lamparello, 2000). CRM classifies customers based on importance and profitability, for examples banks classify their customers into 4 categories :

Platinum customers: These are customers that give more profit and have less expenditure rather than other customers.

Golden customers: This type of customers has lower profitability rather than previous type but more expenditure.

Leaden customers: This type of customers has lower profitability and uses the most services that cause higher expenditure.

Ferrous customers: This type of customers has no considerable profitability and only uses bank for bill payments and cash money receiving .

In this article, key customers are listed in two first types, because they are effective in bank's profitability. In addition, electronic banking means using advanced software and hardware technologies based on network and telecommunication to transfer financial information electronically which eliminate physical presence of customer (Nami et al. 2008). These services are much diversified in the world and a few are used in Iran. Current services are internet banking, mobile banking, telephone banking and ATM's that we refer to all as electronic services in this article. 
Gholamian et al. (2011) provided a recommender system model based on collaborative filtering to improve the customer profile in collaborative systems to enhance the recommender system efficiency. This improvement was accomplished using time context and group preferences and their experimental results demonstrated that the proposed model had a better recommendation performance than existing models.

\subsection{The proposed framework of the method}

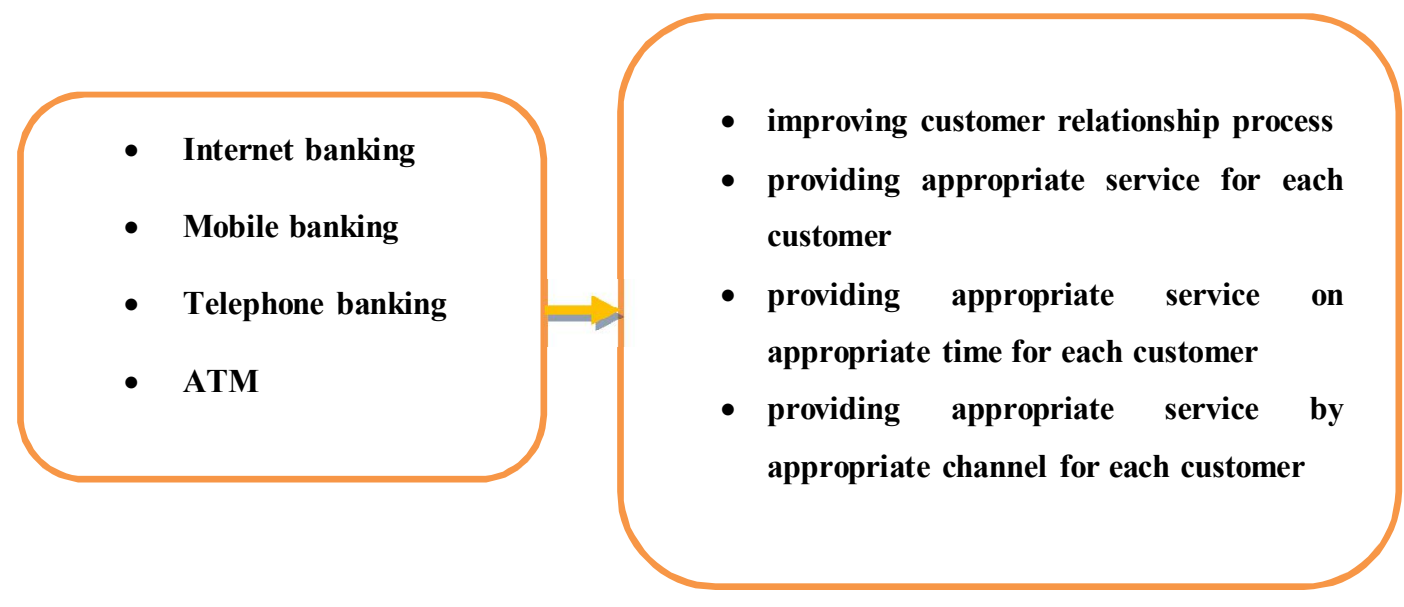

Fig. 2. The proposed study

The proposed study of this paper considers the following hypotheses,

1. E-banking services have positive effect on key CRM components.

2. Every e-banking service has identical effect on key CRM components and has no significant differences.

3. Each CRM component has identical affectability by e-banking services.

4. Internet banking service influences on key CRM components.

5. Mobile banking service influences on key CRM components.

6. Telephone banking service influences on key CRM components.

\section{ATM influences on key CRM components.}

This study is an applicable one and questionnaire has been used as data collection tool. In this study, theoretical framework, conceptual model, its components and research literature is collected by library resources. A 20 case questionnaire with Likert spectrum has been provided. Questionnaire validity has been confirmed by five university professors and five banking experts. For reliability, Cronbach's alpha has been used and Table 1 demonstrates the summary of our findings,

\section{Table 1}

Cronbach's alpha of each electronic service

\begin{tabular}{lcc}
\hline Items & Questions & Cronbach's alpha \\
\hline Mobile banking & 5 & 0.868 \\
Internet banking & 5 & 0.909 \\
ATM & 5 & 0.88 \\
Telephone banking & 5 & 0.803 \\
\hline Total & 20 & 0.902 \\
\hline
\end{tabular}


Survey's statistical population is key customers of Mellat bank's branches in Tehran. Mellat bank has 39 division managers in which Tehran has 6 divisions with 6 managers. As banking expert suggested and also regarding customers' exposure to these e-banking services, division 5 was selected. In our survey, 102 people were selected, randomly. T-Student and Friedman test have been used to measure the significance of averages and ranking the components. Fig. 3 shows details of personal characteristics of participants,

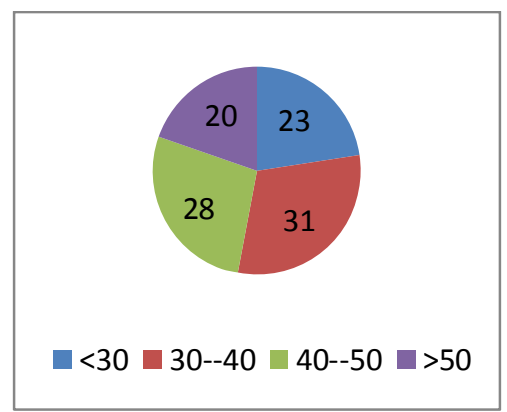

Frequency of Age (\%)

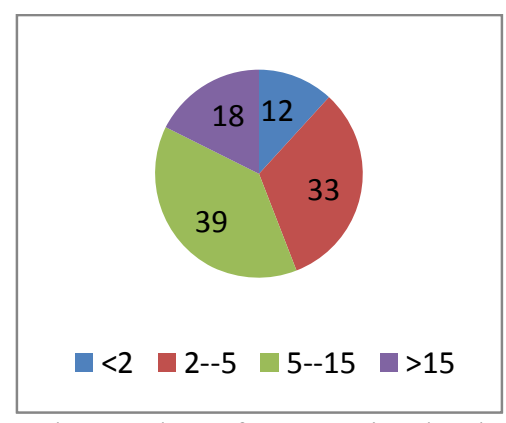

The number of years using bank

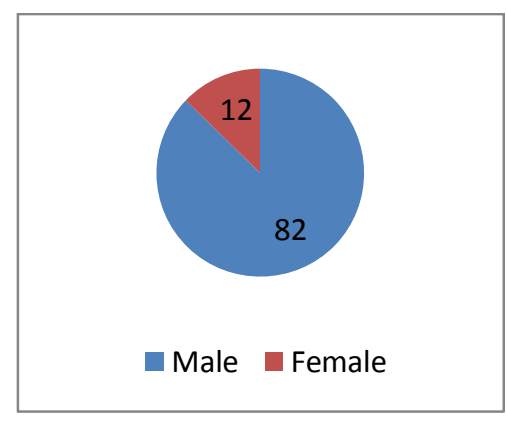

Gender $(\%)$

Fig. 3. Personal characteristics of the participants

\section{The results}

We first present the summary of our findings on testing various hypotheses and Table 2 demonstrates the summary of our findings.

\section{Table 2}

The summary of t-student

\begin{tabular}{|c|c|c|c|c|c|}
\hline Item & Title & Average & Deviation & Statistics & Sig. \\
\hline 1 & Internet Banking Effects on Key Customers Relationship Management & 3.91 & 0.81 & 3.3 & 0.000 \\
\hline 2 & Mobile Banking Effects on Key Customers Relationship Management & 3.7 & 0.82 & 35.73 & 0.000 \\
\hline 3 & Telephone Banking Effects on Key Customers Relationship Management & 3.89 & 0.72 & 42.45 & 0.000 \\
\hline 4 & ATM Effects on Key Customers Relationship Management & 4.06 & 0.83 & 38.46 & 0.000 \\
\hline
\end{tabular}

As we can observe from the results of Table 2, all four hypotheses have been confirmed and Table 3 and Table 4 show details of our findings on Freedman test.

Table 3

The results of ranking different factors using Freedman test

\begin{tabular}{ll}
\hline Electronic Services & Rank \\
\hline Internet banking & 2.56 \\
Mobile banking & 2.25 \\
Telephone banking & 2.48 \\
ATM & 2.7 \\
\hline
\end{tabular}

As we can observe from the results of Table 3, access to ATM machines is the most important factor followed by Internet banking, telephone banking and mobile banking. In addition, based on the results of Table 4, we realize that customer relationship process is the most important factor followed by providing appropriate service for each customer, providing appropriate service by suitable channel for each customer.

\section{Table 4}

The results of ranking different CRM factors using Freedman test

\begin{tabular}{ll}
\hline Electronic Services & Rank \\
\hline Customer relationship process & 2.77 \\
Providing appropriate service for each customer & 2.63 \\
Providing appropriate service on suitable time for each customer & 2.19 \\
Providing appropriate service by suitable channel for each customer & 2.41 \\
\hline
\end{tabular}




\section{Conclusion}

In this paper, we have presented an empirical investigation to survey electronic banking effects on key CRM components in one of Iranian banks in city of Tehran, Iran. The survey has designed a questionnaire and distributed it among some experts in one of selected regions and the results have been verified based on t-student and Freedman tests. Results have shown that all electronic banking services influence on CRM but there were no significant differences among effects of electronic services on CRM. Each CRM component had different effects on electronic services. In fact, according to freedman test, improving customer relationship process was the most important factor followed by providing appropriate service for each customer, providing appropriate service on appropriate time for each customer and providing appropriate service by appropriate channel for each customer. There were some limitations on this study: Key customers were very busy and they tend to respond to questions barely. Returned questionnaires were low. In future studies we suggest considering other items (rather than internet banking, telephone banking, mobile banking and ATM). Every e-banking item can be considered and reviewed by researchers in terms of different perspectives.

\section{Acknowledgement}

The authors would like to thank the anonymous referees for their comments on this paper.

\section{References}

Ayadi, O. F. (1996). Marketing of bank services, regulation, and bank profitability in an emerging banking system. African Review of Money Finance and Banking, 107-120.

Bennett, H., Durkin, M.G. (2002). Developing Relationship; Culture case in retail banking. The International Journal of Bank Marketing, 20 (5), 200-201.

Buttle, F. (2012). Customer relationship management. Routledge.

Devlin, J., \& Ennew, C. T. (1997). Understanding competitive advantage in retail financial services. International Journal of Bank Marketing, 15(3), 73-82.

Diacon, S.R., Ennew, C.T. (1996). Ethical issues in insurance marketing in UK. European Journal of Marketing, 30 (5), 67-80.

Gholamian, M., Fathian, M., Julashokri, M \& Mehrbod, A. (2011). Improving electronic customers' profile in recommender systems using data mining techniques. Management Science Letters, 1(4), 449-456.

Hyung, S.K., Young, G.K., \& Chan, W.P. (2010). Integration of firm's resource and capability to implement enterprise CRM: A case study of a retail bank in Korea. Decision Support Systems 48, 313-322.

Kotler, P. J., \& Armstrong, G. M. (2010). Principles of marketing. Pearson Education.

Kumar, V. (2010). Customer relationship management. John Wiley \& Sons, Ltd.

Lamparello, D. (2000). Doing More for the Right Customers. Bank Systems and Technology Magazine, 37 (1), 110-111.

Meyer, C., \& Schwager, A. (2007). Understanding customer experience. Harvard business review, 85(2), 116.

Nami, M.R., \& Hamdolahzade, S. (2008). Electronic Banking; challenges and necessities. $2^{\text {nd }}$ e-banking conference.

Salami, M. P. (2005). Impact of customer relationship management (CRM) in the Iran banking sector. International journal of organizational innovation, 2(1), 225-251.

Sweeny Group. What is CRM? http://www.sweeneygroup.com/crm.htm,7/24/00 accessed 2000. Marketing \& Ecommerce, Published by CRM urgu.com, 2002.

Tyler, K., Stanley, E. (1999).UK bank corporate relationships: large corporate expectations of service. International Journal of Bank Marketing, 17 (4), 158-170.

Wyner, G.A. (1999).Customer relationship measurement. Marketing Research Journal, 11, 39 - 41. 